\title{
ethic \\ COSMOPOLITISMO EM HABERMAS: COM KANT PARA ALÉM DE KANT
}

\section{COSMOPOLITISM IN HABERMAS: WITH KANT BEYOND KANT}

\author{
CHARLES FELDHAUS ${ }^{1}$ \\ (UEL/Brasil)
}

\begin{abstract}
RESUMO
Este estudo pretende mostrar como Habermas baseado no projeto de Immanuel Kant de uma ordem mundial pacífica restrita ao direito à hospitalidade universal e a uma estrutura jurídica federativa voluntária termina desenvolvendo uma concepção de direito internacional muito mais robusta que inclui uma estrutura quase estatal, embora ele seja enfático em afirmar que é um regime de governança mundial sem um Estado global. Habermas desenvolve sua concepção não apenas num debate com o esboço de uma paz perpétua de Kant, mas também considerando as inovações normativas que ocorreram nos mais de duzentos anos que se passaram desde a formulação original em 1795.
\end{abstract}

Palavras-chave: Cosmopolitismo; Direito internacional; Direitos humanos; Paz; Coerção.

\begin{abstract}
This study aims to show how Habermas based on Immanuel Kant's project of a peaceful world order restricted to the right to universal hospitality and a voluntary federative legal structure ends up developing a much more robust conception of international law that includes an almost state structure, although it is emphatic in asserting that it is a world governance regime without a global state. Habermas develops his conception not only in a debate with Kant's outline of a perpetual peace, but also considering the normative innovations that have occurred in the more than two hundred years that have passed since the original formulation in 1795.
\end{abstract}

Keywords: Cosmopolitism; International law; Human rights; Peace; Coercion.

No final das contas, a censura contra uma política moralizadora repousa numa falta de clareza conceitual, pois a almejada instauração de um Estado de cidadania global significaria que violações dos direitos humanos não seriam julgadas e combatidas, em primeiro lugar, sob pontos de vistas morais, porém seriam perseguidas como ações criminais no âmbito de uma ordem jurídica estatal. Ora, uma juridicização abrangente das relações internacionais não é possível sem o estabelecimento de procedimentos de solução de conflitos. E a institucionalização desses procedimentos irá 
proteger o tratamento jurídico das violações dos direitos humanos contra um obscurecimento moral do direito $\mathrm{e}$ impedir uma discriminação moral completa dos 'inimigos' (Habermas, 2003, p. 47).

\section{Introdução}

A obra de Immanuel Kant Zum ewigen Frieden. Ein philosophischer Entwurf $(1795)^{2}$ teve e ainda tem uma influência no pensamento político contemporâneo, o que certamente não pode ser negligenciado. O número de traduções nos mais diversos idiomas desse opúsculo ainda se proliferam durante o tempo e com a fundação da Liga das Nações pelo presidente americano Woodrow Wilson o projeto kantiano de uma ordem pacífica e duradoura pela primeira vez na histórica da humanidade começou a encontrar um lugar na vida política concreta (HABERMAS, 2004, p. 154155). Certamente, Habermas reconhece que Wilson nunca fez qualquer tipo de referência ao livro de Kant em seu programa de uma liga de paz no período que sucedeu à Primeira Guerra Mundial, contudo, quando ele apresentou o esboço do projeto da Liga das Nações alguns intelectuais alemães reconheceram prontamente que a visão de Kant de uma ordem mundial pacífica ecoava no projeto do presidente americano (HABERMAS, 2004, p. 154-5). O fato que a proposta de Kant da criação de uma federação de Estados orientada ao objetivo de uma paz mundial ou algo muito similar tem obtido espaço no terreno da realidade, mostrou que o projeto não era uma mera quimera, não era algo apenas de interesse histórico e filosófico, mas se tornou um objetivo coletivo da espécie humana.

É preciso reconhecer que a proposta inicial de Wilson não teve o êxito esperado, uma vez que poucos anos depois o mundo se encontrou diante de outro conflito bélico de grandes proporções e as Nações Unidas pouco puderam fazer, se algo puderam, para evitar a Segunda Guerra Mundial. Não obstante, Habermas acredita que existem diferenças substantivas entre o documento que fundou a Nações Unidas e aquele que posteriormente fundou a Organização das Nações Unidas logo após o final da segunda grande guerra supracitada. Ele compreende que a Carta das Nações Unidas de 1945 contém inovações normativas que possibilitam identificar esse documento com uma constituição, mesmo que essa não tenha sido criada com a intenção de constituir uma constituição global (HABERMAS, 2004, 159).

O que equivale a dizer que a proposta de Kant desenvolvida no contexto histórico do século XVIII não estacionou como uma mera peça de museu e que, apesar do distanciamento histórico de mais de duzentos anos com modificações importantes, tem ganhado corpo como um 
empreendimento coletivo da espécie humana. É digno de nota que, apesar de ocupar um papel central na consolidação de instituições orientadas à paz duradoura, os Estados Unidos da América mudaram de postura no passar dos anos, se recusando a se orientar pelas decisões do Conselho de Segurança da ONU, por exemplo, o que inclusive levou Habermas a identificar uma outra alternativa mais preocupante no cenário internacional, a saber, a do liberalismo hegemônico.

No que segue, esse estudo mostra, em primeiro lugar, que houve alguma oscilação na concepção de direito internacional de Kant (I); que, a despeito dessa oscilação quanto à estrutura jurídica da ordem mundial orientada à paz duradoura, o espírito da obra de Kant (uma vez que seria mais controverso se basear apenas no que diz a letra) estaria ainda comprometido com uma república mundial e que a federação de Estados livres é apenas um substituto temporário, contudo, insuficiente para garantir o fim visado, razão pela qual Habermas procura uma outra estrutura jurídica intermediária entre a federação de Estados livres e a república mundial à luz do desenvolvimento do direito internacional (II); ao abordar a concepção cosmopolita de Kant, Habermas mostra que a mesma necessita de algumas revisões conceituais e com base na análise da proposta de Kant sugere reformas na própria estrutura da Organização das Nações Unidas (III); mesmo que Habermas tenha partido da concepção de direito cosmopolita kantiana para formular sua própria visão acerca do tema, sua abordagem em vários aspectos vai para além do que Kant disse em 1793, 1795, e 1797 (IV); por fim, são feitas algumas breves considerações a respeito da concepção de Kant e Habermas no que diz respeito à justiça distributiva na esfera internacional $(V)$.

\section{Algumas variações na concepção cosmopolita de Kant}

Como já foi dito, Habermas acredita que a concepção de cosmopolitismo que Kant desenvolve em seus pequenos escritos políticos precisa ser complementada, mas em alguns aspectos se poderia dizer que precisa até mesmo ser corrigida. Emprego a expressão "pequenos escritos políticos" porque, a despeito do que muitos poderiam pensar, Kant não trata de uma ordem mundial pacífica apenas no opúsculo À paz perpétua (1795), mas também apresenta alguns aspectos gerais a respeito do tema na última parte de outro opúsculo igualmente célebre Sobre a expressão corrente: o que pode ser correto em teoria, mas não tem uso na prática (1793), em que trata especificamente da relação entre teoria e prática respondendo à posição de Moses Mendelssohn (1729-1786) em Jerusalém ou sobre o poder religioso e judaísmo (1783), obra em que o ganhador do prêmio da 
Academia de Ciências de 1763 defende uma posição cosmopolita, porém numa perspectiva filantrópica, portanto ética, e não jurídica, que consiste exatamente no ponto de divergência entre ambos. Kant diz: "Da minha parte (...) confio na teoria que dimana do princípio de direito (...) de maneira a introduzir-se assim um tal Estado universal dos povos" (KANT, 1995 , p. 101; AA 08.313). Nessa terceira parte desse opúsculo de 1793, Kant responde também à objeção realista de que uma paz duradoura seria uma quimera. A objeção realista pode fazer sentido contra uma ordem mundial pacífica baseada numa perspectiva ética ou filantrópica, mas perde em plausibilidade quanto aplicada a uma perspectiva jurídica baseada, ao menos nesse momento do projeto kantiano, num Estado universal de povos (KANT, 1995, p. 101; TP, AA 08: 313). Como é sabido, em 1795 Kant publicou o opúsculo À paz perpétua, no qual Kant modifica a estrutura jurídica de uma ordem global pacífica baseada no "Estado universal de povos" ou "república mundial" por uma "federação de sociedades civis" ou "uma federação antagônica à guerra" (KANT, 1995, p. 136; ZeF, AA 08: 357). Em A metafísica dos costumes (entre as seções §53-62) (1797), Kant trata novamente do direito internacional na parte final da Doutrina do direito. Kant sustenta nesse momento de seu desenvolvimento intelectual que a forma jurídica de uma ordem internacional pacífica deve ser um tipo de união que não deve possuir nenhum poder soberano, o que somente pode acontecer numa constituição civil, mas somente uma confederação ou aliança que pode ser revogada de tempos em tempos (KANT, 2011, p. 239; MS, AA 06: 351). Kant denomina essa união agora de "congresso permanente de Estados" (KANT, 2011, p. 238-9; MS, AA 06: 350-1) em A metafísica dos Costumes.

Esta oscilação quanto à estrutura jurídica de uma ordem mundial pacífica mostra para Habermas que Kant estava incerto a respeito de qual forma jurídica seria mais adequada para alcançar o objetivo almejada de uma paz duradoura. Essa mudança de posição por parte de Kant levou os comentadores a especular a respeito das razões da mudança de opinião, a respeito do tipo de contradição que poderia estar envolvida na noção de Estado mundial ou global. Se pode perguntar até mesmo se houve uma mudança radical entre a posição de 1793 e a de 1795 e 1797 ou se trataria muito mais de uma mudança de ênfase. As passagens textuais nem sempre são claras quanto ao tipo de contradição ou podem até mesmo sugerir uma contradição conceitual, uma contradição empírica ou uma contradição pragmática. Compartilho da interpretação de Pauline Kleingeld (2004, p. 304) que sustenta que não existe nenhuma contradição envolvida no conceito de Estado mundial ou global para Kant. Ela sustenta que a razão para a mudança na estrutura jurídica de uma ordem mundial orientada à 
paz duradoura não consiste nem numa contradição conceitual, nem numa contradição empírica, mas numa contradição entre a noção de Estado mundial e a natureza do próprio direito internacional. Kant (KANT, 1995, p. 147; ZeF, AA 08: 354, 367) afirma que o direito internacional [Völkerrecht] consiste numa pluralidade de Estados diferentes e separados. Por conseguinte, se o direito internacional é uma pluralidade de diferentes Estados por definição, então a forma jurídica adequada não poderia ser um Estado global. Além disso, Kleingeld considera errôneo dizer, como os críticos às vezes sugerem, que uma federação de Estados livres pouca ou nenhuma diferença poderia fazer no sentido de promover uma paz duradoura. Uma vez que a existência de uma federação de Estados livres claramente faz diferença na solução dos conflitos bélicos, é mais fácil encontrar uma solução para um conflito entre diferentes países em combate quando se tem uma instância independente para lidar com a situação do que quando não se tem tal instância. Uma instância imparcial é muito mais capaz de dialogar e intermediar uma solução ao conflito do que os próprios Estados envolvidos no conflito poderiam obter com líderes com o raciocínio nublado pelo calor da guerra.

\section{O republicanismo e a questão da estrutura jurídica adequada}

Entretanto, eu tenderia a afirmar que interpretações da posição de Kant em $\dot{A}$ paz perpétua como a de Friedrich Schlegel, que se orientam muito mais pelo espírito da obra de Kant do que pelas dificuldades da letra, podem ser mais promissoras em compreender a posição do pensador. Schlegel mantém, em Versuch über den Begriff der Republikanismus (1796), a república mundial como um ideal ou como uma ficção (como ele costuma denominar). É pertinente lembrar aqui que, na passagem de $\dot{A}$ paz perpétua, em que Kant introduz a federação de Estados livres sem leis coercitivas e sem o poder de um Estado como substituto de um Estado mundial ou de uma república mundial, ele diz expressamente que essa alternativa deve ser escolhida apenas sob a condição que os povos não estejam preparados para aceitar a ideia positiva de um Estado de povos. Apenas sob a condição que os povos não estejam preparados para aceitar in hipothesi o que é correto in thesi (uma república mundial), a federação de Estados livres em expansão contínua é a única maneira de evitar injustiça e inimizade no mundo (KANT, 1995, p. 136; ZeF, AA 08: 357). Se pode dizer que a federação de Estados livres ou o foedus pacificum é a única maneira de assegurar a confiança no direito (KANT, 1995, p. 134-5; ZeF, AA 08: 356). A obrigatoriedade [Verbindlichkeit] do direito internacional exige ao menos uma federação de Estados livre para auxiliar na arbitragem 
dos conflitos bélicos. Habermas considera que a forma jurídica proposta por Kant é insuficiente, particularmente se presta atenção à maneira como Kant define "congresso permanentes de Estados" na versão de 1797: "Uma união voluntária de diferentes Estados, suscetível de ser dissolvida a qualquer momento, e não uma união (como a dos Estados americanos) que esteja baseada numa Constituição política e que seja, portanto, indissolúvel" (KANT, 2011, p. 239; MS, AA 06: 351). O congresso permanente ou a federação de Estados livres carece do atributo da permanência e esse aspecto incomoda seriamente Habermas. Ele (HABERMAS, 1996, p. 208-9) considera que para ser consistente, a noção de uma liga duradoura tal como proposta por Kant, deveria assumir funções de Estado e ser baseada numa constituição. Ela deveria, diferentemente do que propõe Kant na citação acima, assumir e não recusar o tipo de união que existia entre os estados americanos, uma união baseada numa constituição e por isso dotada do estatuto da permanência e capaz de fazer valer suas decisões diante dos Estados membros. A obrigatoriedade [Verbindlichkeit] implicada na noção de "direito" em direito internacional somente poderia ser alcançada para Habermas com uma estrutura jurídica mais robusta, o que Habermas considera que de alguma forma está sendo implementado com as inovações normativas ocorridas no direito internacional principalmente após o final da Segunda Guerra Mundial. É sempre bom lembrar que a proposta de Habermas pretende ser idealista, mas não no sentido pejorativo, por isso também seria "realista". O realismo da proposta resulta em grande medida da estratégia reconstrutiva. Ele procura reconstruir seu conceito de direito internacional a partir do que tem sido feito através de tratados internacionais, de julgamentos de crimes após conflitos bélicos, etc. No pensamento de Habermas (EDGAR, 2006, p. 130), as "ciências reconstrutivas transformam um saber-como [know-how] num saber-que [saber-que]" e dessa maneira o que Habermas faz, ao tratar do direito internacional, é trazer à consciência no fenômeno jurídico analisado, nesse caso a esfera internacional, aquelas inovações normativas que estavam implícitas no atos jurídicos realizados principalmente desde a fundação das Nações Unidas em 1919 e incluir essas inovações normativas numa concepção de direito internacional inspirada em Kant mas que vai para além de Kant exatamente por considerar o desenvolvimento posterior do direito internacional.

Se pode dizer que existe também alguma confusão da função de certos argumentos que Kant emprega contra o Estado mundial, como se fossem contra a noção de Estado mundial em si, quando na verdade se dirigem apenas a uma forma de governo mundial específica. Kant (1995, p. 147; ZeF, AA 08: 367) argumenta em $\dot{A}$ paz perpétua contra uma 
monarquia mundial, especificamente contra uma monarquia mundial implementada de maneira heterônoma. Kant rejeita uma monarquia mundial por causa do modo como ela agrega gradualmente os outros Estados do mundo em si. Não é um processo voluntário, mas um processo orientado pelo emprego da violência e da coerção por um Estado hegemônico. Aqui provavelmente encontra-se como pano de fundo a reação à Revolução Francesa e os terrores que se seguiram a esse ato revolucionário.

Pauline Kleingeld (2004, p. 305) sustenta que Kant não abandonou em $\dot{A}$ paz perpétua a concepção que um estado mundial (república mundial). Ele ainda é a solução ao problema da guerra. É preciso lembrar que o caráter pacífico das repúblicas não é suficiente para assegurar a paz, mesmo que importante na garantia da paz duradoura. A posição de Kant implica num aumento do número de repúblicas juntamente com a federação de Estados livres como substituta viável a uma república mundial. Não apenas a tese do caráter pacífico das repúblicas, não apenas a tese de que a federação de Estados livres garante a paz. Se poderia dizer que Rawls coloca grande ênfase na tese democrática (republicana) em $O$ direito dos povos; mas que Habermas coloca grande ênfase na estrutura jurídica internacional, por isso foca nas deficiências da federação de Estados livres e nas razões da mudança.

Algo menos evidente na proposta de Kant diz respeito à relação entre o republicanismo e a república mundial e o federalismo de Estados livres. A noção de Kant de republicanismo implica os princípios a priori da razão: liberdade, igualdade e dependência (KANT, 1995, p. 127-8; TP, AA 08: 34950). Se esse é o caso na esfera global, seja ela federativa, seja ela um Estado global, esses princípios teriam consequências para o tratamento da instituição legal global em relação aos Estados e em relação aos indivíduos como cidadãos do mundo ou como cidadãos cosmopolitas. Eles (cidadãos do mundo e dos Estados) teriam que ter respeitada sua liberdade nas relações mútuas segundo uma lei universal assim como em suas relações diante do seu próprio Estado de pertença ou até mesmo dos Estados em que eles decidem exercer seu direito de visita, teriam que receber tratamento igual de sua pátria e provavelmente dos Estados em que foram permitidos permanecer por um certo período de tempo, e por fim as decisões que os obrigam deveriam depender não apenas de uma constituição nacional, mas provavelmente de uma constituição global, contudo, Kant não aprofundou na especificação da natureza da federação de Estados livres e na estrutura legal exata que essa deveria possuir, por assim dizer, no que uma república mundial seria. 
É importante observar aqui que Friedrich Schlegel em uma resenha de À paz perpétua publicada no periódico Deutschland em 1796, portanto apenas um ano após a publicação do opúsculo, defende algumas modificações na proposta kantiana, e por conseguinte no espírito da obra de Kant, mesmo que em alguns momento contra a letra da obra de Kant, entende que a paz perpétua exige não apenas o republicanismo de Estados particulares, mas até mesmo o republicanismo mundial. Schlegel sustenta que o imperativo categórico político derivado do imperativo categórico moral exige que todos os Estados se tornem paulatinamente repúblicas ou assumam modos republicanos de governar. Contra a letra de Kant, ou ao menos, contra o que tem sido considerado a visão padrão do pensamento de Kant sobre direito internacional (nas palavras de Pauline Kleingeld (2012, p. 190-193)), a república mundial permanece sempre no horizonte como uma ficção política. Fiç̧ão entendida como um ideal, como uma ideia que deve orientar a conduta política dos seres humanos no caminho de uma paz duradoura. Se aceitamos que a posição de Schlegel representa de fato o espírito do pensamento de Kant, então se poderia dar mais ênfase à passagem em que Kant apresenta a 'federação' como um substituto e compreender como Schlegel que o Estado mundial, mesmo que contraditório com o conceito de direito internacional, permanece como um ideal, porque um ideal por definição também é inalcançável. Também contra Kant, Schlegel sustenta que a democracia representativa é um modo de governo republicano. Schlegel afirma que não apenas a democracia não é incompatível com o republicanismo, "portanto, o republicanismo é necessariamente democrático" (SCHLEGEL, 1984 [1796], p. 110). Schlegel considera que Kant confundiu a democracia com a oclocracia quando excluiu a democracia das formas de governo tradicionais que poderiam ser exercidas de maneira republicana, dado que Kant pensava que a democracia seria exercida necessariamente de maneira despótica. Se o próprio Kant tivesse prestado atenção ao seu critério de forma de governo, que implica que toda forma de governo é representativa, teria contemplado a possibilidade da democracia representativa. A democracia representativa não é mais suscetível de ser governada de modo despótico do que outras formas de governo como a aristocracia e a monarquia. Somente a oclocracia estaria sujeita com alto grau de probabilidade à ditadura da maioria contra alguma minoria. Contra Kant, Schlegel também aponta arbitrariedade no critério de inclusão dos cidadãos portadores do direito ao voto. Kant exclui do direito ao voto mulheres e homens que sejam incapazes de se manter a si mesmos. 


\section{Do escrutínio do esboço kantiano à paz perpétua à reforma das Organização das Nações Unidas}

Depois da publicação de sua principal obra de filosofia do direito, Faktizität und Geltung. Beitrage zur Diskurstheorie des Rechtes and des demokratischen Rechtsstaats [Direito e democracia. Entre Facticidade e Validade] em (1997[1992]), Jürgen Habermas desenvolveu significativamente sua concepção de democracia deliberativa para além das fronteiras nacionais. Ele desenvolve sua concepção de direito internacional numa interlocução constante com o processo de consolidação da União Europeia e com o projeto de Immanuel Kant. É interessante observar como, apesar de procurar se filiar de alguma maneira com a proposta de Kant, Habermas acaba defendendo uma concepção de direito internacional muito mais robusta do que a de Kant. Kant restringiu o direito cosmopolita apenas ao direito de hospitalidade universal, que consiste no direito que todo ser humano enquanto cidadão do mundo de visitar aos demais países, mas esse direito não é um direito de permanência em países estrangeiros. Muito menos um direito de estabelecer colônias, aqui é importante lembrar que Kant era um crítico enfático do sistema de estabelecimento de colônias praticado ao redor do mundo pelos países europeus de seu período histórico.

Além disso, Habermas (1996, p. 192) afirma que o projeto de Kant foi talhado conforme à ideia de direito racional e com base no horizonte histórico sob o qual Kant viveu. Ainda que se possa dizer que o projeto não estacionou, dado que ganhou corpo no terreno da realidade, porém, o projeto precisaria de algumas revisões conceituais. Habermas (2004, p. 158) sustenta que as inovações normativas que ocorreram no direito internacional nesse meio tempo superam significativamente o que foi contemplado na proposta de uma federação de Estados livres de Kant. O conceito de paz, ao qual recorre Kant para tratar de uma ordem mundial pacífica, é um conceito meramente negativo, vinculado à ideia de ausência de conflito bélico ou militar. Esse conceito negativo deixa de prestar atenção ao fato que as guerras também podem ser travadas por motivos baseados em desigualdades sociais, razão pela qual enfrentar as desigualdades sociais e não apenas eliminar os conflitos bélicos existentes deve ser um objetivo permanente de uma ordem pacífica orientada a uma paz duradoura como imaginada originalmente por Immanuel Kant em 1795 (HABERMAS, 1996, p. 216). Não apenas Kant se restringiu a um conceito de paz negativo, mas também teria ignorado que tanto o comércio internacional quanto a publicidade poderiam promover a guerra e não apenas a paz. Habermas acredita que Kant imaginava que o comércio internacional seria 
uma motivação importante para afastar os Estados do mundo do ato de guerrear. Dessa maneira, Kant teria ignorado o fato que muitas guerras são travadas exatamente por interesses comerciais. Em síntese, Habermas (1996, p. 215) acredita que Kant teria pensado em termos ainda não históricos e por causa disso ignorou esses aspectos conceituais. É preciso acrescentar, que Kant considerou o princípio da publicidade como um instrumento de solucionar os conflitos entre a moral e a política na esfera internacional e com isso aumentar a probabilidade de uma ordem global pacífica. Habermas acredita que Kant ignorou que a esfera pública pode ser não apenas um espaço de esclarecimento, mas também um espaço de manipulação de massas.

Desse modo, Habermas propõe uma revisão dos conceitos fundamentais do esboço de um projeto filosófico orientado a uma paz duradoura de Kant nos seguintes aspectos: primeiramente, como o conceito de uma liga ou de uma federação de Estados livres não é consistente com o fim proposto, a saber, assegurar uma paz duradoura entre os povos. É necessário identificar outro tipo de estrutura jurídica que seja consistente com o fim proposto. Em síntese, Habermas entende que o tipo de estrutura jurídica proposta por Kant em $\dot{A}$ paz perpétua e em $A$ metafísica dos costumes deixa de prestar contas ao caráter obrigatório (o que se costuma chamar de Obligatio, Verbindlichkeit, Verbindung, ou pura e simplesmente de necessidade prática [Notwendigkeit]), o que normalmente está presente em qualquer ordem jurídica doméstica. Em outras palavras, a ordem jurídica orientada à paz duradoura proposta precisa carregar consigo a ideia de necessidade prática envolvida na ideia de obrigação de cumprir as normas de qualquer sistema jurídico doméstico, o que pode implicar a ameaça de sanção na esfera internacional aos comportamentos que desviam das normas do direito internacional, em especial por atos de violação dos direitos humanos e pelo empreendimento de guerra de agressão. Em segundo lugar, Kant ainda estava vinculado a um conceito de soberania absoluta e indivisível, razão pela qual a federação de Estados livres era pensada como uma união de Estados e não como uma união de cidadãos cosmopolita [Weltbürgerbund]. Kant atribuí ao ser humano enquanto ser humano apenas o direito à hospitalidade universal, se poderia sustentar que mesmo quando Kant defende ou proíbe certas tipos de conduta durante o conflito bélico no sexto artigo preliminar $\dot{A}$ paz perpétua (KANT, 1995, p. 124; ZeF AA 08: 346-7) e no parágrafo cinquenta e sete de A metafísica dos costumes (KANT, 2011, p. 233-4; MS, AA 06: 347-8) ele não está recorrendo aos direitos humanos tal como compreendidos contemporaneamente, mas apenas a necessidade de se manter a confiança 
nos contratos, nesse caso específico dos contratos de paz, que para que uma paz duradoura seja possível exige uma confiança mútua forte.

Não por acaso Habermas sustentou como consequência disso que Kant tinha dificuldade em pensar a questão da atribuição de responsabilidade às pessoas que cometessem crimes durante a prestação de serviços ao Estado durante uma guerra (HABERMAS, 1996, p. 211). O que somente se tornou possível depois que as cortes internacionais julgaram os atos cometidos durante a Segunda Guerra Mundial. Pode ser dito aqui que o direito internacional no que diz respeito ao modo de governo necessário à implementação do regime dos direitos humanos e à garantia de uma paz duradoura, "nesse meio tempo (...) [se desenvolveu] para além de Kant" (HABERMAS, 1996, p. 211). Embora Kant não tenha dito explicitamente isso, geralmente se supõe que os membros de uma federação de Estados livres deveriam ser todos governados de maneira republicana, ou ao menos se esperar que isso ocorra de maneira paulatina. Talvez a ordem dos artigos definitivos dê a impressão que todos os Estados precisam ser repúblicas para ser membros da federação de Estados livres, uma vez que o primeiro artigo trata da exigência de que os Estados se tornem paulatinamente repúblicas e o segundo artigo da exigência que deve ser estabelecida uma federação de Estados livres. Não obstante, o fato é que a Organização das Nações Unidas reúne quase todos os Estados do mundo atual sem considerar se o governo do respectivo Estado é republicano ou não, democrático ou não.

No que diz respeito à natureza pacífica das repúblicas, Kant não poderia ter previsto a força da ideia de 'nação' e o ressurgimento do 'nacionalismo', embora Habermas reconheça que essa tese não era completamente falsa (HABERMAS, 1996, p. 200). Além do mais, "as pretensões [Forderungen] históricas e estatísticas mostram (...) que estados com constituições democráticas não fazem menos guerras do que regimes autoritários" (HABERMAS, 1996, p. 200). O que a história tem mostrado é que democracias não costumam empreender guerras mutuamente. No que diz respeito ao comércio mundial, Kant não teria percebido que interesses comerciais não apenas poderiam ser uma motivação em favor da unificação pacífica dos povos, mas também uma motivação para empreender guerras na disputa por novos mercados. 0 comércio mesmo poderia se tornar uma razão para fazer a guerra e não uma razão para recear empreender a guerra. No que diz respeito à esfera pública, Kant teria assumido de maneira equivocada que a esfera pública e a publicidade teriam uma função de controlar a política e isso limitaria os conflitos bélicos. Aqui Habermas parece estar se referindo a sua tese de livre docência publicada como livro como $A$ mudança estrutural da esfera 
pública. Investigação quanto a uma categoria da sociedade burguesa, um livro em que ele procura mostrar como a esfera pública emergiu como um espaço de transparência e discussão pública baseada em argumentos razoáveis nos Cafés europeus, mas acabou se tornando o contrário, a saber, um meio de manipulação de massas com o surgimento da indústria cultural. Em outra oportunidade (FELDHAUS, 2012, p. 126-7) eu já teci algumas considerações a respeito dessas três críticas de Habermas em relação ao projeto de Kant de uma ordem mundial pacífica, mas agora por mor da brevidade gostaria apenas de observar que, primeiramente, o argumento de Kant não precisa da validade absoluta da tese que as democracias ou as repúblicas (para empregar o termo específico de Kant) sejam pacíficas, precisa apenas que exista uma tendência nas democracias a adotar uma posição menos belicosa, visto que juntamente com a tese do caráter pacífico das repúblicas opera o aspecto institucional de uma federação de Estados livre como meio de arbitragem de conflitos; em segundo lugar, não parece óbvio que Kant ignorasse completamente os efeitos produtores de conflito do comércio internacional, visto que o mercantilismo era prática corrente em seu período histórico e o argumento de Kant precisa novamente apenas de uma tendência à adoção de uma atitude menos belicosa e não de uma necessidade absoluta; em terceiro lugar, embora acredito que aqui Habermas possa ter mais razão do que na crítica às outras duas tendências, não é completamente claro que o critério da publicidade tal como foi compreendido por Kant como meio de conciliar a moral e a política e como pedra de toque da legitimidade das leis ignore que a linguagem pública poderia ser empregada como instrumento de manipulação de massas.

\section{Habermas com Kant para além de Kant}

Retornando agora à questão da opção de uma liga, de um congresso ou uma federação de Estados livres em relação à proposta da terceira parte do texto de 1793, pode ser dito que algumas críticas de Habermas contra a concepção de Kant são equivocadas. Habermas sustenta que Kant escolheu substituir a república mundial por uma federação de Estados livres por não perceber que era possível existir uma constituição sem todo o aparato estatal. Entretanto, se concordamos com a observação de Kleingeld (2004, p. 304) que Kant não rejeita toda forma de Estado global ou mundial, mas apenas uma forma específica de estrutura estatal global, a saber, uma monarquia global que se impõe a maneira de um império, o argumento de Habermas parece perder alguma plausibilidade. Habermas está equivocado em dizer que Kant não contemplou a alternativa de uma ordem jurídica mundial constitucional como era o caso da sociedade norte americana, uma 
vez que faz referência explicita a essa característica do modelo federativo americano. É mais provável que Kant não considerasse o modelo federativo baseado numa constituição americano como uma alternativa adequada ao seu "esboço" de um projeto orientado à paz duradoura. Habermas pode estar certo que o modelo de uma federação de Estados livres é insuficiente como garantia da paz duradoura, mas obviamente, Kant não pôde detalhar tanto nem poderia contar com os recentes desenvolvimentos históricos de seu próprio projeto, desde a fundação das Nações Unidas pelo presidente americano Wilson, quando estava construindo seu esboço de projeto. Essa é a razão por que a proposta de Habermas com Kant vai além de Kant em detalhes essenciais da ordem global orientada à garantia da paz. Habermas dá corpo e conteúdo ao ideal cosmopolita e republicano de Kant. Mas esse conteúdo não se origina única e exclusivamente das ideias do filósofo e sociólogo alemão, mas surge em grande medida dos desenvolvimentos que o esboço de um projeto orientado à paz duradoura obteve após alcançar o terreno da realidade com a fundação das Nações Unidas em 1919 pelo presidente americano Wilson e os desdobramentos posteriores com a reformulação do projeto inicial na fundação da Organização das Nações Unidas, os tribunais de guerra em Nuremberg e Kyoto, entre outros eventos relevantes. E nesse sentido Habermas tem toda razão, o projeto não estacionou, a história avançou e muitas das inovações normativas contidas nesses atos jurídicos internacionais não poderiam nem ser imaginados pelo filósofo de Königsberg.

Habermas, por outro lado, pode pensar à luz dos recentes desenvolvimentos históricos na esfera do direito internacional e contemplar a necessidade de transformar a assembleia da ONU num tipo de parlamento mundial com duas casas. Uma casa com representantes dos cidadãos do mundo. Outra casa com representantes dos Estados. Habermas também pode levar em conta as falhas do sistema de controle criado com a fundação das Nações Unidas, desde 1919. Se pode citar como exemplo o sistema de votação do Conselho de Segurança da ONU centrado no sistema de vetos pelas grandes potências e as distorções que tal sistema costuma produzir. Habermas pode testemunhar o grande risco de arbitrariedade contido nesse sistema de votação e como tal modelo coloca água no moinho do realismo político que acusa o sistema de controle de direitos humanos como carregado de empregos ideológicos. Para evitar esse emprego ideológico do discurso e do controle do cumprimento dos direitos humanos, é necessário realizar reformas no sistema de votação do Conselho de Segurança e na constituição do próprio Conselho de Segurança, a fim de melhor espelhar o sistema de forças das sociedade global atual. Habermas defende a inclusão de novos membros no Conselho de Segurança e a modificação no sistema 
de votação orientado pelo veto de grandes potências, ele defende o sistema de votação orientado pelo voto da maioria. Mesmo as grandes potências deveriam poder ter suas decisões contrariadas pela instituição global responsável pela promoção da paz e pelo controle do cumprimento dos direitos humanos. Portanto, isso exige a possibilidade de exigir o cumprimento das decisões acordadas. Por essa razão que Habermas defende a criação de uma força militar própria da ONU, a fim de poder fazer valer as decisões tomadas pela própria instituição. Contra Kant e além de Kant, Habermas não propõe a abolição dos exércitos permanentes, mas a criação de um exército mundial para coagir o cumprimento das decisões da atual instituição global que procura garantir a paz e implementar os direitos humanos. Mas com Kant, Habermas acredita que o estabelecimento de uma instituição internacional para arbitrar os conflitos é conditio sine qua non de uma paz duradoura entre Estados. Talvez o que Habermas no fundo quisesse dizer, como afirma Kleingeld (2012, 190-1), "é [que] a visão que Kant deveria ter advogado [é] uma federação internacional mais forte a ser produzida através de meios democráticos".

Conforme Habermas (1996, 208), quando Kant desenvolve uma nova concepção de ordem jurídica como meio de alcançar o fim último visado, essa nova estrutura jurídica não se mostra suficientemente adequada como meio de alcançar o fim visado, porque parece faltar uma institucionalização que seja capaz de vincular aos governos dos Estados particulares. O mesmo problema está presente de alguma maneira na ordem jurídica internacional atual. Tanto a federação de Estados livres de Kant quanto a ONU carecem de poder de sanção adequada para suas decisões. O problema, conforme Habermas (2004, p. 126-7), é o resultado da miopia kantiana em relação a um modelo alternativo de constitucionalismo existente já em seu período histórico. Kant se apegou ao caso específico da república francesa recém fundada após a Revolução Francesa e deixou de prestar atenção ao modelo de constitucionalismo liberal do caso específico dos Estados Unidos da América. O modelo francês ainda estava vinculado à noção de soberania como indivisível e que por isso vetaria qualquer tipo de organização jurídica mais robusta do que apenas uma federação de Estados livres como substituto de uma república mundial. O modelo norte-americano contemplava a possibilidade de uma soberania dividida e por isso seria possível pensar uma instituição jurídica com competências diferentes daquelas atribuídas aos Estados locais.

Habermas (2004, p. 132) sustenta que a república mundial como um ideal da razão com papel apenas regulativo é um modelo falso tal como concebido por Kant em À paz perpétua. Em vez disso ele desenvolve um sistema de governança global sem um Estado mundial. Desse modo, se 
pode afirmar que, mesmo que Habermas discorde ou considere inadequados os motivos, ou prováveis motivos para a recusa de um Estado global, Habermas não considera um Estado global como uma solução ao problema da garantia da paz mundial e do regime de implementação dos direitos humanos. Habermas pensa isso porque acredita que não é necessário possuir a forma estatal a fim de ter uma constituição mundial. Kant não percebeu essa alternativa conceitual entre uma república mundial e uma federação de Estados livre ou um congresso permanente de Estados. É interessante observar que, a despeito de não atribuir uma instituição estatal no sentido forte do termo, o sistema do direitos internacional desenvolvido por Habermas possui vários atributos geralmente vinculados ao Estado como um parlamento com duas casas, o poder militar supranacional e coercitivo para fazer valer as decisões tomadas, uma reforma na estrutura do Conselho de Segurança, entre outros.

\section{A questão da justiça distributiva na esfera global}

Agora pretendo brevemente fazer algumas observações a respeito da questão da redistribuição global. O termo cosmopolitismo é geralmente empregado na filosofia política contemporânea para se referir a concepções de direito internacional que conferem um papel muito importante aos problemas de redistribuição global. No que diz respeito à posição de Kant, pouco pode ser dito a respeito de sua posição sobre redistribuição global, visto que esse tema não aparece em seus textos de modo explícito. Kant é na melhor das hipóteses omisso em relação a esse ponto. Habermas, por outro lado, não pode ser considerado omisso em relação a esse ponto, ele se manifesta explicitamente, embora Habermas (2009, p. 118) afirma explicitamente que sua discussão não deve seguir o caminho de uma discussão filosófica sobre a justiça, mas deve ser apresentada e discutida com base em princípios fundamentais que se orientam pelas premissas determinadas institucionalmente. Resta ainda ser considerado se Habermas reconhece a influência de agentes internacionais na produção da assimetria de riqueza global e se esse fator tem um impacto direto na concepção do dever de assistência global no pensamento de Habermas.

No modelo de Habermas os problemas de redistribuição global são competência do segundo nível, o nível transnacional. A razão para isso resulta do diagnóstico realizado em outras obras anteriores em relação ao papel da globalização no enfraquecimento da capacidade do Estado em cumprir suas obrigações de prestar assistência aos seus cidadãos, uma vez que o Estado com a globalização tem perdido o controle das condições econômicas. Em obra como Para reconstrução do materialismo histórico e 
Era de transições, Habermas discorre sobre a crise de legitimidade no capitalismo tardio e como o processo de globalização tem ocasionado déficits de legitimidade tanto pela incapacidade crescente do Estado nacional de lidar com as crises econômicas, quanto pelo crescimento da complexidade das sociedades atuais no que diz respeito ao pluralismo cultural. Por causa disso, Habermas defende a necessidade de expandir a concepção de democracia deliberativa para além da esfera doméstica, para a esfera internacional, a fim de frear os imperativos sistêmicos do mercado que lentamente tem corroído a capacidade dos Estados nacionais de cumprir suas funções e tem minado a base da legitimidade estatal. Apenas uma democracia deliberativa cosmopolita pode tratar de maneira adequada com os desafios das sociedades globalizadas e plurais contemporâneas. Dessa maneira, Habermas parece comprometido com uma visão a respeito do direito internacional que se opõe a concepções igualitárias mais amplas como a defendidas pelos defensores do cosmopolitismo como Thomas Pogge, que advoga um dever de assistência global mais amplo a todos os seres humanos, não por que são cidadãos de um Estado particular, mas por que são cidadãos do mundo. Contudo, diferentemente da concepção de Rawls (Nussbaum suscita essa objeção contra a concepção de Rawls), a concepção de Habermas não está comprometida com a hipótese da base doméstica da redistribuição global de recursos ao redor do globo terrestre. Habermas não deixa de considerar a influência de atores globais na produção da desigualdade de riqueza mundial. Entretanto, não é óbvio como a posição de Habermas evitaria a possibilidade de resultar do modelo de democracia deliberativa aplicado à esfera global apenas um dever de assistência limitado. Se o parlamento mundial ou os agentes internacionais que compõem o nível transnacional optarem por um dever de assistência muito limitado, não se poderia dizer que essa posição não é compatível com a posição de Habermas, desde que todos os afetados sejam incluídos no grupo que realiza a deliberação a respeito disso.

\section{Considerações finais}

Como foi possível observar, Habermas partiu de uma avaliação do projeto de uma ordem cosmopolita, de uma ordem pacífica, de Kant, a fim de desenvolver sua própria concepção de direito internacional com três níveis de competências. Habermas encontra-se entre os leitores do pensamento jurídico internacional de Kant que assume que ele recusa qualquer tipo de estrutura global estatal, embora foi possível mostrar que essa interpretação não é carente de problemas. Estudiosas do pensamento de Kant como Pauline Kleingeld acreditam que Kant não recusou 
completamente o Estado mundial, mas apenas a monarquia universal. A posição de Kleingeld parece ser compartilhada pela visão republicana de Friedrich Schlegel que desenvolve o que na época era entendido na Alemanha como o espírito e não a letra da obra de Kant. Outros pensadores que procuram seguir o espírito e não a letra foram Friedrich Schiller, Johann Gottlieb Fichte, entre outros. Schlegel sustenta que a república mundial é uma ficção política ou um ideal que sempre permanece no horizonte do projeto kantiano à paz duradoura. É necessário o republicanismo local, dos Estados particulares, mas também o republicanismo universal, de um Estado mundial, a fim de alcançar o fim almejado de uma paz duradoura. Habermas, por sua vez, contou com a história e o desenvolvimento recente do direito internacional para empreender seu diagnóstico dos fracassos e realizações do projeto de Kant de uma ordem pacífica mundial. Nesse sentido, Habermas pode incorporar em sua continuação do esboço do projeto de Kant as inovações normativas que surgiram com a criação das Nações Unidas, da Organização das Nações Unidas, dos tribunais penais internacionais ocorridos após a Segunda Guerra Mundial, etc. Com isso, Habermas desenvolve uma concepção do direito internacional com Kant para além de Kant que inclui reformas na estrutura da Organização das Nações Unidas, no que diz respeito ao Conselho de Segurança da ONU, a criação de um parlamento mundial, a constituição de uma força militar mundial, entre outras. 


\section{Notas}

${ }^{1}$ Professor Associado da Universidade Estadual de Londrina e do Programa de PósGraduação em Filosofia (mestrado e doutorado acadêmico) da Universidade Estadual de Londrina (UEL), Londrina, PR. Brasil. E-mail: charlesfeldhaus@gmail.com. Orcid-iD: 0000-0001-6889-0239.

2 Todas as citações da obra de Immanuel Kant seguem o padrão da edição da Academia de Ciências de Berlim, mas também incluem a referência padrão autor data das traduções empregadas em cada caso. 


\section{Referências bibliográficas}

EDGAR, Andrew. Habermas. The Key Concepts. London: Routledge, 2006.

FELDHAUS, Charles. 2012. Teria Habermas se equivocado ao ler Zum ewigen Frieden de Immanuel Kant? In: TONETTO, M. C.; PINZANI, A; DALL'AGNOL, D. Investigações Kantiana I: um debate plural. Florianópolis: Funjab, 2012.

HABERMAS, Jürgen. Mudança estrutural da esfera pública. Investigações quanto a uma categoria da sociedade burguesa. Tradução de Flávio R. Klothe. Rio de Janeiro: Tempo Brasileiro, 1984.

. Die Einbeziehung des Anderen. Studien zur politischen Theorie. Frankfurt: Suhrkamp, 1996.

. A inclusão do outro. Estudos de teoria política. Tradução de George Sperber e Paulo Astor Soethe. São Paulo: Edições Loyola, 2002.

. Era de Transições. Tradução de Flávio Beno Siebeneichler. Rio de Janeiro: Tempo Brasileiro, 2003.

. O ocidente dividido. Tradução de Bianca Tavolari. São Paulo: Editora Unesp, 2016 a.

. Para a reconstrução do materialismo histórico. Tradução de Rúrion Melo. São Paulo: Editora Unesp, 2016b.

KANT, Immanuel. Kants Werke. Akademie Berlin, Walter de Gruyter \& Co., 1968.

. A paz perpétua e outros opúsculos. Trad. Artur Morão. Lisboa: Edições 70, 1995.

A metafísica dos Costumes. Tradução de José Lamego. Lisboa: Fundação Calouste Gulbenkian, 2011.

. Der gespaltene Westen. Frankfurt: Suhrkamp, 2004.

Ay, Europa! Tradução espanhola de José Luis López de Lizaga, Pedro Madrigal e Francisco Javier Gil Martín. Madrid: Editorial Trotta, 2009.

KLEINGELD, Pauline. Approaching Perpetual Peace: Kant's Defense of a League of States and his Ideal of a World Federation. In: European Journal of Philosophy, v. 12, n. 3, 304-325, 2004.

. Kant and Cosmopolitanism. The Philosophical Ideal of World Citizenship. Cambridge: Cambridge University Press, 2012. 
MENDELSSOHN, Moses. Jerusalem, or on Religion Power or Judaism. English Translation by Allan Arkush. Massachusttes: Brandeis University Press, 1983.

MERTENS, Thomas. "From 'Perpetual Peace' to 'The Law of Peoples': Kant, Habermas and Rawls on International Relations." Kantian Review 6:60-84. doi:10.1017/S1369415400001606.], 2002.

POGGE, Thomas. Realizing Rawls. London: Cornell University Press, 1989.

RAWLS, John. The Law of People. With the "Idea of Public Reason Revisited". Cambridge: Havard University Press, 1999.

. O direito dos povos. Tradução de Luís Carlos Borges. São Paulo: Martins Fontes, 2004.

SCHLEGEL, Friedrich. Versuch über den Begriff des Republikanismus. Veranlasst durch die Kantische zum ewigen Frieden. In: Immanuel Kant Zum ewigen Frieden. Mit Texten zur Rezeption 1796-1800. Leipzig: Reclam, 1984. 